\title{
Diseño de un cuestionario para valorar la competencia en comunicación oral del alumnado de Magisterio
}

\author{
Iris Orosia Campos Bandrési(i) \\ Universidad de Zaragoza, Zaragoza, España \\ María Jesús Colón Castilloi"ie \\ Universidad de Zaragoza, Zaragoza, España \\ Marta Sampériz Hernándeziii(i) \\ Universidad de Zaragoza, Zaragoza, España
}

\begin{abstract}
Resumen
El Espacio Europeo de Educación Superior contempla el desarrollo de la competencia comunicativa como cuestión fundamental en los planes de formación en Magisterio, por lo que es oportuno profundizar en el conocimiento de las percepciones que las y los futuros maestros tienen sobre su competencia oral y sobre la formación recibida en este aspecto en la titulación. En esta línea, se presentan el diseño y validación de un cuestionario con 156 estudiantes de Magisterio. Los resultados avalan la solidez de la herramienta y la exploración de las valoraciones del alumnado muestra la incidencia de variables como el sexo y la experiencia académica o profesional previa. Además, destaca la correlación negativa entre la valoración de la formación recibida y el curso, con una valoración insuficiente entre el alumnado que se encuentra finalizando la titulación.
\end{abstract}

\section{Palabras clave}

Comunicación oral. Educación Infantil. Educación Primaria. Formación de docentes.

\section{Modelo de um questionário para avaliar a competência em comunicação oral dos alunos nos cursos de formação de professores no Magistério}

\begin{abstract}
Resumo
O Espaço Europeu de Ensino Superior contempla o desenvolvimento da competência comunicativa como uma questão fundamental nos planos de formação de professores. Portanto, faz-se necessário aprofundar 0 conhecimento das percepções que futuros professores têm sobre sua competência oral e sobre a formação recebida nesse aspecto ao longo do curso. Neste sentido, são apresentados o modelo e a validação de um questionário com 156 professores em formação. Os resultados confirmam a solidez da ferramenta e a exploração das avaliações dos alunos mostra a incidência de algumas variáveis, como sexo, experiência acadêmica ou profissional. Além disso, destaca-se a correlação negativa entre a avaliação da
\end{abstract}


formação recebida e o curso, com uma avaliação insuficiente entre os alunos que estão concluindo o curso.

\title{
Palavras-chave
}

Comunicação oral. Educação Infantil. Educação Primária. Treinamento de professor.

\section{Design of a questionnaire to evaluate trainee teachers' oral} communication skills

\begin{abstract}
The European Higher Education Area considers the development of communicative competence as a fundamental issue in the teacher training plans. Thus, it is appropriate to deepen the knowledge on the perceptions that future teachers have about their oral competence and about the training that they have received in this aspect throughout the teaching training degree. In this line, the design and validation of a questionnaire with 156 teachers of teaching training is presented. The results verify the solidity of the tool. In addition, the exploration of student evaluations shows the incidence of some variables such as sex or previous academic or professional experience. In addition, the negative correlation between the evaluation of the training that they have received, and the course stands out, with an insufficient evaluation among the students who are finishing the degree.
\end{abstract}

\section{Keywords}

Teacher training. Oral communication. Preschool Education. Primary Education.

\section{Introducción}

Tras la Declaración de Bolonia y la consolidación del actual Espacio Europeo de Educación Superior - proceso desarrollado entre 1997 y 2010 -, entre las competencias destacadas en los planes de formación del Grado de Magisterio, las habilidades comunicativas resultan fundamentales por su implicación en las tareas que requieren el ejercicio profesional de la docencia.

En primer lugar, las bases epistemológicas de la educación del siglo XXI ponen de manifiesto la importancia de la comunicación en la adquisición del conocimiento. Las teorías interaccionistas y socioconstructivistas expuestas por autores como Vygotsky (2000) o Bruner $(1986,1991)$ han hecho énfasis en el impacto que el lenguaje oral tiene sobre la capacidad del aprendizaje desde la infancia y su trascendencia en la escuela. Los avances en la Didáctica de las Lenguas y el desarrollo del enfoque comunicativo han incidido igualmente en la necesidad de priorizar la competencia oral en las aulas, cuestión que implica una revisión constante de los planes de formación del profesorado, de su 
concepción de la enseñanza de las lenguas y de las bases teóricas en las que se sustentan (LOMAS; OSORO; TUSÓN, 1993). Al mismo tiempo, en coherencia con la Teoría Social del Aprendizaje de Bandura (1984), es necesario que el profesorado se presente como un modelo de hablante adecuado, ya que su discurso no solo incide en la adquisición lingüística del alumnado, sino que también es un referente ante las familias y otros agentes sociales. Así, Rosales (2013) diferencia tres grupos de competencias específicas que ha de adquirir el maestro en formación: competencias para el estímulo del aprendizaje - ligadas al aula -, competencias vinculadas a los contextos de intervención - colaboración con el claustro, las familias y otras instituciones del entorno escolar - y competencias curriculares específicas - que suponen la colaboración entre iguales y con otros profesionales. Todas ellas requieren la interacción en diferentes contextos e implican el dominio de la comunicación oral. En este sentido, resulta de interés investigar sobre las percepciones (MATOS; JARDILINO, 2016) que los estudiantes de Magisterio tienen en relación con su competencia oral y qué papel atribuyen a la formación recibida en la carrera universitaria.

\section{Estado de la cuestión}

Como línea de investigación, el estudio de la competencia oral en los estudiantes de Magisterio ha recibido un interés creciente, tanto desde un punto de vista teórico (BALAGUER; FUENTES; PALAU, 2015) como práctico (GRÀCIA et al., 2019; OREJUDO; FERNÁNDEZ-TURRADO; BRIZ, 2012).

Entre los trabajos de naturaleza descriptiva, los estudios de Domingo et al. (2010), Domingo, Gallego y Rodríguez (2013) o Gallego y Rodríguez (2014, 2015, 2018) descubren una autovaloración deficitaria entre los estudiantes en relación con sus habilidades comunicativas como docentes, en coherencia con el análisis realizado por el propio profesorado de la titulación de Magisterio. Entre sus resultados, también se observa una mejor autopercepción entre el alumnado de los cursos superiores, así como una presencia generalizada de autovaloraciones más positivas en relación con las habilidades de recepción frente a las de expresión oral.

Por lo que respecta a estudios fundamentados en la intervención, las aportaciones de Gràcia et al. (2019) y Orejudo, Fernández-Turrado y Briz (2012) destacan la importancia de la reflexión del alumnado sobre sus estrategias en comunicación oral. Según estos 
estudios, la reflexión explícita es más eficaz que un trabajo implícito en las asignaturas, ya que: "[...] 9 horas de intervención del programa de habilidades de comunicación logran mejorar más la autoeficacia que cuatro meses de asistencia a clases ordinarias" (OREJUDO; FERNÁNDEZ-TURRADO; BRIZ, 2012, p. 211).

Aunque se trata de una línea de investigación de interés creciente, como apuntan Gràcia et al. (2019), los estudios sobre las habilidades orales de los maestros en formación son todavía escasos. En la misma línea, Gallego y Rodríguez (2014) destacan que son necesarios estudios que aborden la cuestión desde las percepciones de los maestros en formación respecto a su competencia en comunicación oral en las diferentes dimensiones que el ejercicio docente contempla.

\section{Diseño metodológico de la investigación}

\subsection{Objetivos del estudio}

Desde este marco teórico, la investigación se fundamenta en los siguientes objetivos:

1. Diseñar un cuestionario para el estudio de la percepción de los maestros y maestras en formación respecto a su competencia en comunicación oral y a la formación recibida en este aspecto en los estudios en Magisterio.

2. Explorar las percepciones de los estudiantes en las diferentes dimensiones que componen la competencia en comunicación oral del docente en formación y descubrir sus principales dificultades, así como su valoración acerca de la formación recibida.

3. Identificar algunas variables asociadas a una mejor autopercepción de la competencia en comunicación oral de los maestros y maestras en formación.

\subsection{Enfoque metodológico}

El estudio se desarrolló bajo un diseño cuantitativo no experimental de tipo encuesta mediante cuestionario cerrado, en el que se incorporó una pregunta abierta con el fin de triangular o ampliar los datos cuantitativos. Se trata de una investigación 
transversal y exploratoria, ya que su propósito es "[...] comenzar a conocer una variable o un conjunto de variables, una comunidad, un contexto, un evento, una situación. Se trata de una exploración inicial en un momento específico" (HERNÁNDEZ; FERNÁNDEZ; BAPTISTA, 2014, p. 155).

\subsection{Contexto y muestra}

La investigación se realizó en el Grado de Magisterio de la Universidad de Zaragoza. Los participantes cursaban esta titulación en los campus de Huesca y Zaragoza. El muestreo implementado fue de tipo no probabilístico y por conveniencia. Se contactó con profesorado de la titulación que puso el cuestionario a disposición del alumnado. Su cumplimentación fue voluntaria y anónima. Se consiguió, así, la participación de 156 alumnos y alumnas (Tabla 1). El alumnado matriculado en esta titulación ascendía entonces a 2.678 estudiantes en los campus citados, de modo que, según un nivel de confianza del $95 \%$ y un margen de error del $5 \%$, era necesaria una muestra de 337 participantes para alcanzar la representatividad. Por tanto, este estudio puede considerarse como una primera aproximación de naturaleza exploratoria al objeto de estudio.

Tabla 1 - Principales características de la muestra

\begin{tabular}{c|c|c|c|c|c|c|c|c|c}
\hline Sexo & $\%$ & Edad & $\%$ & Curso & $\%$ & Campus & $\%$ & Titulación & $\%$ \\
\hline Mujeres & 81,9 & $18-22$ & 70,5 & $1^{\circ}$ & 12,9 & Huesca & 65,2 & Ed. Infantil & 33,3 \\
\hline Hombres & 18,1 & $23-24$ & 12,3 & $2^{\circ}$ & 38,1 & Zaragoza & 34,8 & Ed. Primaria & 66,7 \\
\hline & & $25-30$ & 11,5 & $3^{\circ}$ & 20,0 & & & & \\
\hline & & $30-35$ & 3,8 & $4^{\circ}$ & 29,0 & & & & \\
\hline & & +35 & 1,9 & & & & & & \\
\hline
\end{tabular}

Fuente: Elaboración propia (2020).

\subsection{Instrumento de investigación}

El instrumento utilizado en la investigación fue un cuestionario de 34 ítems de escala tipo Likert de cinco niveles de respuesta cerrada, complementado con una pregunta abierta. El cuestionario pretendía medir la autovaloración de la competencia en comunicación oral de los maestros en formación (25 ítems) y la valoración de la formación recibida al respecto en los estudios de Magisterio (9 ítems). 
Para su diseño, se tomó como referencia el cuestionario de Gallego y Rodríguez (2014), aunque se modificó para adaptarlo a los objetivos de esta investigación. El cuestionario de estos autores cuenta con 63 ítems organizados en cinco dimensiones: competencia como buen emisor; competencia como buen receptor; habilidades comunicativas en clase; competencia para actuar en reuniones con padres o colegas; competencia para ejercer la función de tutor/a.

En esta investigación, además de las destrezas orales asociadas al contexto del centro escolar, interesaba explorar la autopercepción del alumnado respecto a sus habilidades como estudiantes de Magisterio y su valoración sobre la formación recibida en la titulación. El resultado final fue el cuestionario que se adjunta en el Anexo I. Se trata de un instrumento con cuatro partes: en la primera, se recopilan datos de tipo sociodemográfico que configuran las variables independientes - sexo, campus, grado, curso, edad, estudios previos, situación laboral, mención, lenguas habladas, títulos de idiomas; en la segunda, figuran los ítems correspondientes a cada dimensión autoexploratoria - competencia como emisor (Ítems 1-4), competencia como receptor (Ítems 5-9), competencia como estudiante universitario/a (Ítems 10-16), competencia como docente en el aula (Ítems 17-22) y competencia como docente en otras situaciones del centro escolar (Ítems 23-25); en la tercera, se encuentran los ítems relacionados con la valoración de la formación recibida en la titulación de Magisterio (Ítems 26-34). Finalmente, el cuestionario se complementa con una pregunta abierta que permite a los participantes aportar lo que consideren necesario.

\subsection{Validación del cuestionario}

El cuestionario validado de Gallego y Rodríguez (2014), utilizado como punto de partida, ofrecía cierta garantía de fiabilidad. Sin embargo, debido a las modificaciones realizadas, se consideró oportuno analizar de nuevo la validez y fiabilidad del instrumento definitivo.

Para calcular la fiabilidad, se analizó la consistencia interna del cuestionario a través del Alfa de Cronbach. Este coeficiente expresa entre 0 y 1 la intercorrelación o consistencia entre los distintos ítems. Hernández y Mendoza (2018) estiman que el valor 
es aceptable a partir de .70, aunque en investigaciones exploratorias puede serlo desde .60. Los coeficientes fueron elevados y confirmaron la fiabilidad del instrumento (Tabla 2).

Tabla 2 - Resultados del análisis de fiabilidad del cuestionario

\begin{tabular}{c|c|c|c|c|c|c|c|c|} 
& $\begin{array}{c}\text { Com. oral } \\
\text { (total) }\end{array}$ & Emisor & Receptor & $\begin{array}{c}\text { Estudiante } \\
\text { magisterio }\end{array}$ & $\begin{array}{c}\text { Docente } \\
\text { (aula) }\end{array}$ & $\begin{array}{c}\text { Docente } \\
\text { (otros) }\end{array}$ & $\begin{array}{c}\text { Docente } \\
\text { (total) }\end{array}$ & $\begin{array}{c}\text { Formación } \\
\text { recibida }\end{array}$ \\
\hline Alfa Cronbach & .913 & .797 & .781 & .840 & .912 & .853 & .904 & .941 \\
\hline № de ítems & 25 & 4 & 5 & 7 & 6 & 3 & 9 & 9 \\
\hline
\end{tabular}

Fuente: Elaboración propia (2020).

Para calcular la validez del cuestionario, se realizó una prueba de consistencia interna, concretamente un análisis factorial exploratorio. Para ello, previamente, se realizaron el test KMO (Kaiser, Meyer y Olkin) y la prueba de esfericidad de Barlett, cuyos resultados (Tabla 3) permitieron proceder a la realización del análisis factorial exploratorio.

Tabla 3 - Resultados del test KMO y prueba de esfericidad de Barlett

Prueba de KMO y Bartlett

\begin{tabular}{|c|c|c|}
\hline \multicolumn{3}{|c|}{ Prueba de KMO y Bartlett } \\
\hline \multicolumn{2}{|c|}{ Medida Kaiser-Meyer-Olkin de adecuación de muestreo } & .875 \\
\hline \multirow{3}{*}{ Prueba de esfericidad de Bartlett } & Aprox. Chi-cuadrado & 1988,099 \\
\hline & Gl & 300 \\
\hline & Sig. & .000 \\
\hline
\end{tabular}

Fuente: Elaboración propia (2020).

El análisis factorial corroboró la adecuación de las dimensiones, aunque, en cuanto a la competencia en comunicación oral como estudiantes, los ítems se ordenaban en dos subdimensiones que se correspondían, por una parte, con los relacionados con las destrezas empleadas por los estudiantes cotidianamente en el aula y, por otra, con los ítems relacionados con situaciones más formales, de modo que se tuvieron en consideración estas dos subdimensiones y se calculó su fiabilidad con resultados aceptables ( $\alpha .645$ para el caso de la primera y a .813 para la segunda).

\subsection{Tratamiento de los datos}

Para el tratamiento de los datos, se empleó el software SPSS en su versión 15. Se efectuaron tanto pruebas de comparación de medias como análisis correlacionales. Antes de decidir el estadístico a aplicar, se realizaron pruebas de homogeneidad de varianzas mediante la prueba de Levene. Para la comparación de las medias, se 
aplicaron las pruebas ANOVA de un factor o su alternativa no paramétrica, Brown Forsythe. Además, para establecer los grupos entre los que se encontraban las diferencias, se aplicaron las pruebas post hoc de Tukey y Games Howell, según correspondiera.

\section{Resultados y discusión}

\subsection{Autovaloración de la competencia oral}

En términos generales, tal y como refleja el Gráfico 1, se observa una percepción aceptable - en torno al 3 - e incluso positiva - superior al 4 - de la competencia oral por parte de los estudiantes en todas las dimensiones contempladas.

Un análisis más pormenorizado (Gráfico 2) evidencia tendencias similares y diferentes entre el alumnado de los cuatro cursos. En cuanto a las tendencias semejantes, se observa cómo los estudiantes de los cuatro cursos coinciden en valorar favorablemente sus competencias como receptores (Ítems 5 a 9), mientras que perciben más dificultades en las habilidades orales como estudiantes (Ítems 10 a 16). Un ejemplo de ello es la siguiente respuesta ante la pregunta abierta del cuestionario: "A2: Mi principal problema comunicativo es que tiendo a ponerme nerviosa y, por lo tanto, hablo muy rápido, tanto que a veces no se me entiende bien, pero no me doy cuenta hasta que no me lo dice alguien" (Mujer, 3ำ curso, 22 años, trabaja, pero no de cara al público).

Sin embargo, en cuanto a las habilidades relacionadas con la práctica docente (Ítems 17 a 25), parece evidente la distancia entre el alumnado de $1^{\circ}$ y $4^{\circ}$ curso, puesto que las percepciones son más positivas entre los estudiantes que se encuentran en el último curso. Además, es significativo que únicamente el alumnado de $1^{\circ}$ curso valore ítems con una puntuación media insuficiente, en concreto, los referidos a la comunicación en una situación de examen oral y el relacionado con la capacidad de expresarse en el aula ante profesores y compañeros (Ítems 12, 14 y 15). 
Gráfico 1 - Medias generales para cada una de las dimensiones de comunicación oral del cuestionario

5

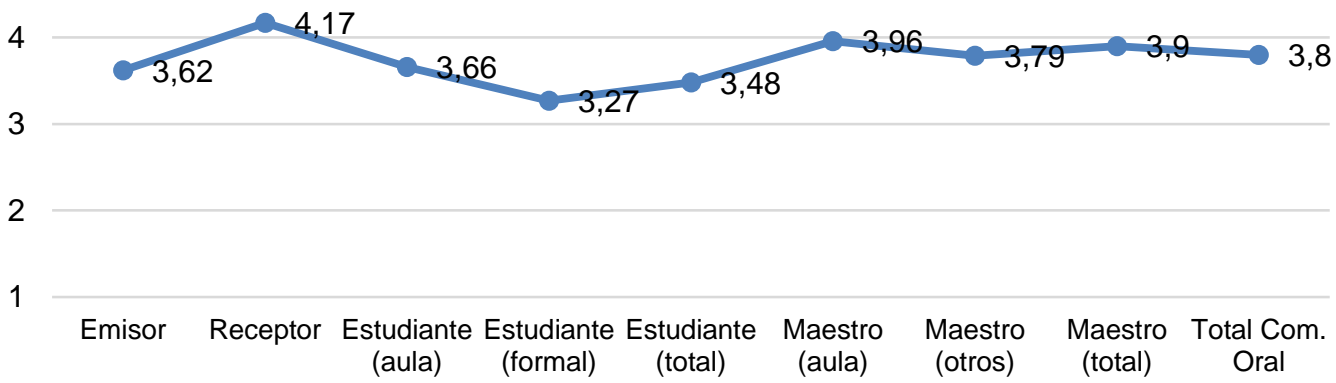

Fuente: Elaboración propia (2020).

Gráfico 2 - Media de los ítems sobre habilidades de comunicación oral por cursos

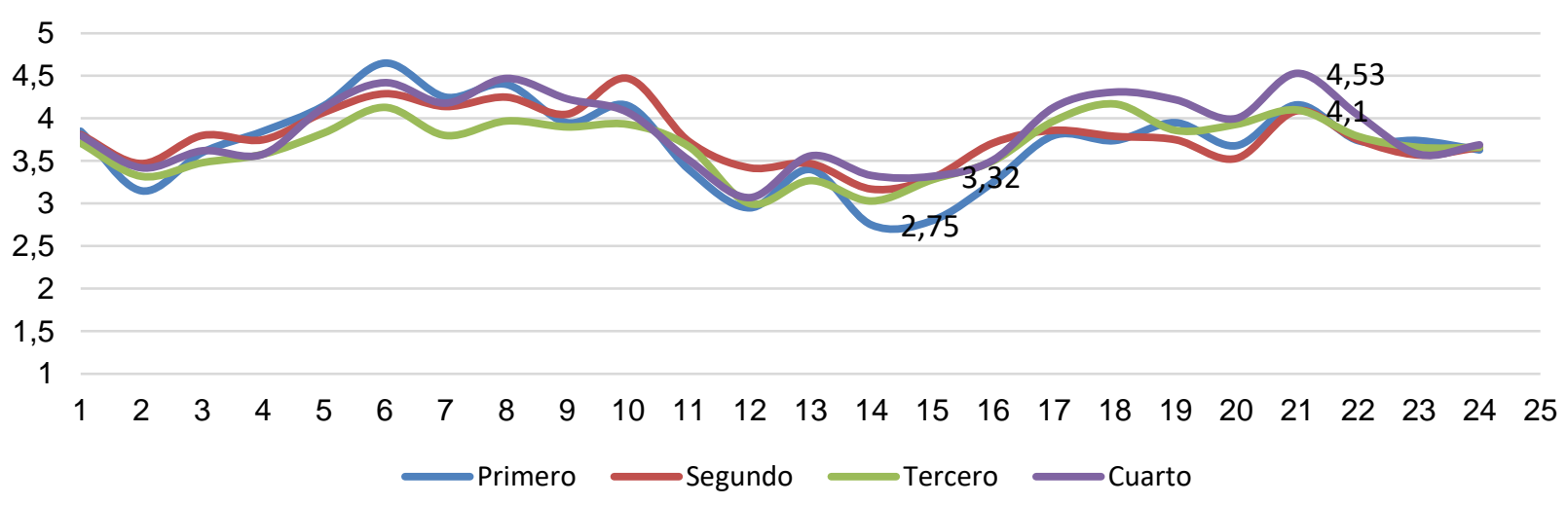

Fuente: Elaboración propia (2020).

Por lo que respecta a las variables independientes, todas ellas - con excepción del Grado de Educación Infantil o Primaria - reportan diferencias significativas (Tabla 4). En primer lugar, la variable sexo parece incidir en los resultados, puesto que los hombres muestran una percepción mejor de sus habilidades comunicativas como docentes que las mujeres (Levene $=1.84, \mathrm{p}=.178 ; \mathrm{F}=6.20 ; \mathrm{p}=.014$ ).

En lo que respecta al curso, las diferencias más sustanciales se encuentran en el caso de las habilidades de comunicación en el aula escolar como docentes (Levene= 1.01, $p=.389 ; F=3.40 ; p=.020)$. La prueba post hoc de Tukey $(p=.015)$ muestra que las diferencias se encuentran entre el $2^{\circ}$ curso $(\mu 3,80)$ y el $4^{\circ}$ curso de la titulación $(\mu 4,21)$.

La variable edad ofrece una tendencia similar en la dimensión de habilidades como estudiante universitario (Levene $=1.15, \mathrm{p}=.332 ; \mathrm{F}=2.06, \mathrm{p}=.037$ ), concretamente $(p=.050)$ entre los que tienen 22 años $(\mu 3,11)$ y los que tienen entre 30 y $35(\mu 4,11)$. De este modo, los que tienen mayor edad tienen una mejor percepción de sus habilidades 
comunicativas. Además, el análisis correlacional a través de la prueba de Pearson reporta un resultado significativo y con una correlación positiva, aunque débil - según los parámetros de Hernández y Mendoza (2018) -, al encontrarse por debajo de .30, entre las habilidades en comunicación oral como estudiante y el factor de la edad.

Tabla 4 - Resultados de correlación de Pearson (com. oral como estudiante-situaciones formales y edad)

\begin{tabular}{|c|c|c|c|}
\hline \multicolumn{4}{|c|}{ Correlaciones } \\
\hline \multirow{3}{*}{ Total_Estudiante } & Correlación de Pearson & Total_Estudiante & VI_Edad \\
\cline { 2 - 4 } & Sig. (bilateral) & 1 &, $202^{*}$ \\
\cline { 2 - 4 } & $\mathrm{N}$ & 147 & 0,014 \\
\hline \multirow{3}{*}{ VI_Edad } & Correlación de Pearson &, $202^{*}$ & 147 \\
\cline { 2 - 4 } & Sig. (bilateral) & 0,014 & 1 \\
\cline { 2 - 4 } & $\mathrm{N}$ & 147 & 156 \\
\hline & \multirow{2}{*}{${ }^{*}$. La correlación es significativa en el nivel 0,05 (2 colas). } & \\
\hline
\end{tabular}

Fuente: Elaboración propia (2020).

Por lo que respecta a la mención o especialidad que cursan o piensan cursar los participantes, también se encuentran diferencias. Así, la autovaloración media (Levene= $1.78, p=.184 ; F=4.50, p=.036$ ) es superior en el caso de aquellos que apuestan por una especialización en lenguas - inglés, francés, aragonés o educación bilingüe - $(\mu 3,97)$ respecto al resto de menciones $(\mu 3,76)$. Estar en posesión de otra titulación (Levene= $2.56, p=.081 ; F=6.88, p=.001$ ) es, asimismo, una variable de incidencia, de forma que el alumnado con una titulación previa universitaria $(\mu 3,89)$ tiene mejor percepción de sus habilidades orales en situaciones formales en el ámbito universitario $(p=.002)$ que los que no cuentan con ninguna $(\mu 3,14)$. Finalmente, la situación laboral también parece influir en la autovaloración de las competencias como estudiantes, especialmente en las situaciones más formales (Levene $=1.28, \mathrm{p}=.387 ; \mathrm{F}=5.35, \mathrm{p}=.006$ ). En concreto, la prueba post hoc de Tukey $(p=.004)$ muestra que estas diferencias se encuentran entre quienes trabajan de cara al público $(\mu 3,50)$ y los que no trabajan $(\mu 3,06)$. En coherencia con ello, en la pregunta abierta del cuestionario, varios informantes responden que han desarrollado más la oralidad en su trabajo y en experiencias cotidianas, complementarias a su formación como docentes, que en las propias aulas de Magisterio:

A4: Considero que las mejores capacidades orales que tengo las he adquirido a través de la experiencia más que en las propias aulas de Magisterio, en el trabajo $y$ en el centro de tiempo libre en los que participo. (Mujer, 3ำ curso, 20 años, trabaja de cara al público). 
A22: Mis habilidades comunicativas las he adquirido enfrentándome a situaciones de mi vida cotidiana y no tanto con cursos o explicaciones de un profesor. Creo que la experiencia te expone al contexto y cada persona tiene que encontrar sus herramientas para mejorar. (Mujer, $2^{\circ}$ curso, entre 30 y 35 años, no trabaja).

A pesar de los resultados expuestos, debe recordarse que el estudio tiene una naturaleza exploratoria y que el tamaño del efecto obtiene unos resultados modestos, salvo en la variable edad, donde aparece $\eta^{2} .132$ para la dimensión relacionada con la competencia oral como estudiante en situaciones formales y $\eta^{2} .120$ para la general.

Tabla 5 - Síntesis de los resultados significativos en la comparación de medias según nuestras VVII

\begin{tabular}{|c|c|c|c|c|c|c|c|c|c|}
\hline & 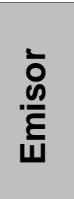 & 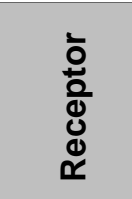 & 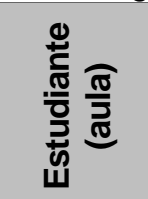 & 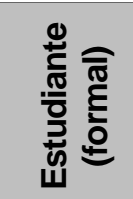 & 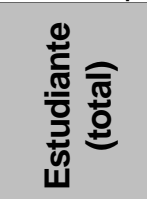 & 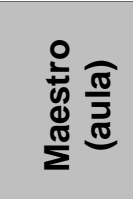 & 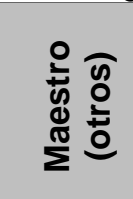 & 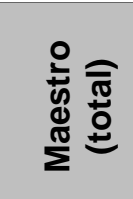 & 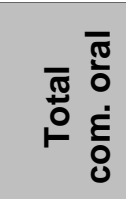 \\
\hline Sexo & & & & & & (p.015) & (p.001) & (p.014) & \\
\hline Curso & & (p.031) & (p.038) & & & & & (p.020) & \\
\hline Edad & & & & (p.019) & (p.037) & & & & \\
\hline Facultad & & & (p.014) & & & & & (p.035) & \\
\hline Mención & & & (p.039) & & & & & & (p.036) \\
\hline T. previa & & & & (p.001) & & & & & \\
\hline Trabajo & & & & (p.006) & (p.015) & & & & \\
\hline
\end{tabular}

Fuente: Elaboración propia (2020).

\subsection{Valoración de la formación recibida en competencia oral}

Por lo que respecta a la valoración de los estudiantes de la formación recibida en competencia oral en el Grado de Magisterio, la puntuación media general es muy limitada $(\mu 3,16)$, puesto que la puntuación mínima posible era de 1 punto. En la pregunta abierta del cuestionario, varios estudiantes muestran la necesidad de incluir más formación sobre oralidad y prácticas comunicativas en las asignaturas de la titulación en Magisterio:

A14: Creo que la formación en cuanto a la competencia comunicativa requerida para la profesión docente por parte de la carrera es muy insuficiente, no tanto a nivel académico (presentaciones orales en clase, etc.) como a nivel de docente (dar clase, preparar tutorías, hablar con familias, etc.). En este último ámbito, no se nos forma y me parece un aspecto fundamental de nuestra futura profesión. (Mujer, $4^{\circ}$ curso, entre 25 y 30 años, trabaja de cara al público).

A3: Creo que en la carrera debería haber una asignatura de oratoria; ya no solo que en las asignaturas ya ofertadas se deba desarrollar más el discurso oral (que también), sino que debería haber una asignatura como tal, ya que la voz y las habilidades comunicativas son las herramientas principales del maestro. En ningún momento se trabaja el cuidado de la voz ni la forma de expresarse ante un público.

Educ. Form., Fortaleza, v. 6, n. 1, e3490, jan./abr. 2021

DOI: https://doi.org/10.25053/redufor.v6i1.3490

https://revistas.uece.br/index.php/redufor/index 
Es algo no entendible siendo que es nuestra mejor aliada en el momento de la docencia. (Mujer, $3^{\circ}$ curso, 22 años, trabaja, pero no de cara al público).

En este aspecto, se encuentran diferencias en función de dos de las variables contempladas - sexo y curso. Así, la percepción de las mujeres $(\mu 3,07)$ es significativamente más negativa (Levene $=.131, \mathrm{p}=.718 ; \mathrm{F}=7.36, \mathrm{p}=.007$ ) que la de los hombres $(\mu 3,57$ ), y también existe una percepción más negativa (Levene $=6.10, p=.001$; $\mathrm{F}=2.96, \mathrm{p}=.036$ ) entre el alumnado que se encuentra finalizando la titulación en $4^{\circ}$ curso ( $\mu$ 2.91) respecto al que acaba de iniciarla en $1^{\circ}$ ( $\mu$ 3.56). En este sentido, al aplicar la prueba correlacional de Pearson se encuentra un resultado significativo $(p=.015)$ y una correlación negativa ( $r=-.199)$, aunque débil.

Gráfico 3 - Media de los ítems sobre habilidades sobre la formación recibida por cursos

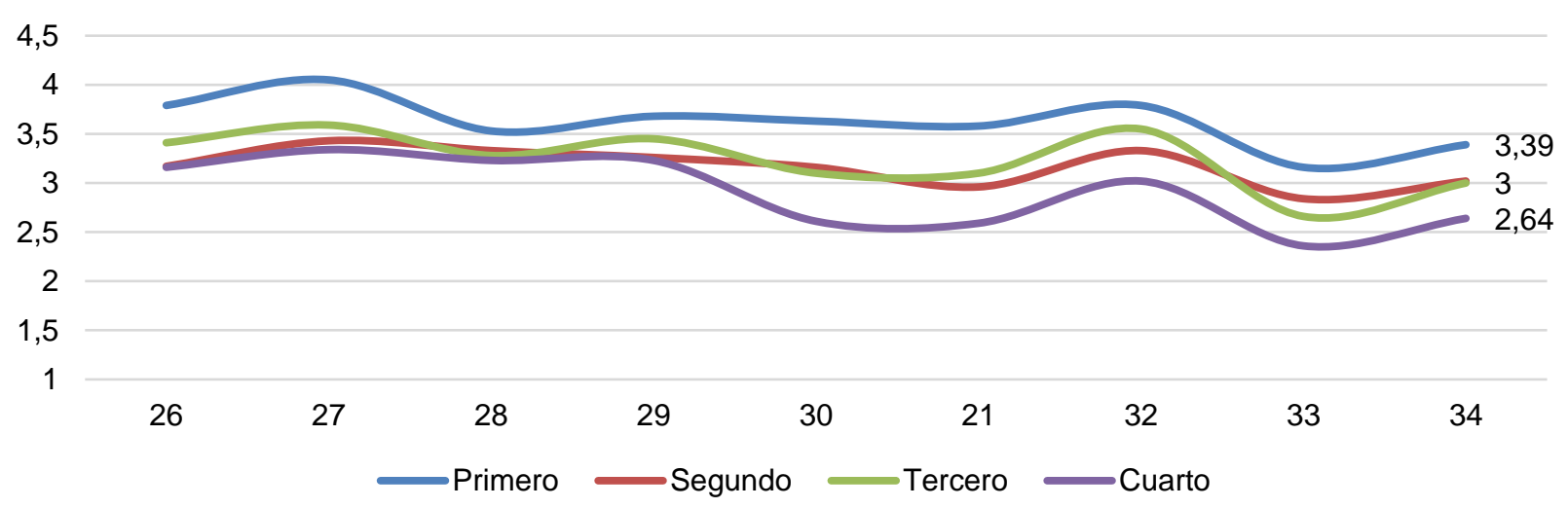

Fuente: Elaboración propia (2020).

Finalmente, los resultados son significativos en diferentes análisis correlacionales. La prueba de Pearson muestra una correlación positiva y de fuerza media entre la percepción de habilidades como emisor y la valoración de la formación recibida en Magisterio $(r=.318 ; p=.000)$. Los que se consideran más competentes en expresión oral valoran mejor la formación recibida en comunicación oral, como la siguiente informante:

A12: El problema es que necesitamos DOCENTES que hayan trabajado como maestros en Primaria. Ellos son los únicos que nos ayudan a desarrollarlas porque son quienes conocen la realidad del aula y se han formado mejor en ello. Tengo miedo de terminar la carrera y no ser lo suficientemente competente en este aspecto. No quiero ser una maestra mediocre. (Mujer, $2^{\circ}$ curso, 20 años, trabaja, pero no de cara al público). 
Sucede lo mismo con la percepción de las habilidades necesarias como estudiantes ante situaciones formales $(r=.298 ; p=.000)$. Así, los que se autovaloran mejor en estas situaciones también valoran mejor la formación recibida. La siguiente respuesta ejemplifica la autovaloración positiva en comunicación oral de una informante vinculada a la valoración positiva de la formación recibida en una asignatura de la titulación: "A20: Esta asignatura [Didáctica de la Lengua Castellana] es la única que me ha dado claves para hacer exposiciones dentro de la universidad' (Hombre, $3^{\circ}$ curso, 25 años, trabaja de cara al público).

La misma correlación presenta la percepción de la competencia oral como estudiante $(r=.369 ; p=.000)$, la que alude a la competencia como docente en el aula $(r=.216 ; p .009)$ y otras relaciones docentes $(r=.317 ; p .000)$. Sucede lo mismo al tener en cuenta la puntuación general de los ítems sobre la comunicación oral $(r=.378 ; p .000)$.

Tabla 6 - Correlación de Pearson (autovaloración de com. oral general y valoración de la formación recibida)

\begin{tabular}{|c|c|c|c|}
\hline \multicolumn{4}{|c|}{ Correlaciones } \\
\hline & & TOTAL_Comunicación & TOTAL_Formación \\
\hline \multirow{3}{*}{ TOTAL_Comunicación } & Correlación de Pearson & 1 &, $378^{* *}$ \\
\hline & Sig. (bilateral) & &, 000 \\
\hline & $\mathrm{N}$ & 141 & 139 \\
\hline \multirow{3}{*}{ TOTAL_Formación } & Correlación de Pearson & $378^{* *}$ & 1 \\
\hline & Sig. (bilateral) &, 000 & \\
\hline & $\mathrm{N}$ & 139 & 149 \\
\hline
\end{tabular}

Fuente: Elaboración propia (2020).

\section{Consideraciones finales}

El primer propósito de esta investigación era diseñar un cuestionario solvente que permitiera estudiar las percepciones del alumnado de Magisterio respecto a su competencia oral y a la formación recibida en la carrera. Los resultados avalan la consistencia del cuestionario creado a partir de la herramienta de Gallego y Rodríguez (2014); en consecuencia, la herramienta se incluye en el anexo del artículo por su posible utilidad en investigaciones semejantes.

En relación al estudio de la percepción del alumnado sobre su competencia comunicativa oral, el análisis exploratorio arroja una autovaloración inferior de sus habilidades como emisor que como receptor; la expresión oral se percibe además como 
especialmente limitada en las situaciones de comunicación más formales. El análisis sugiere también el impacto de algunas variables, principalmente el sexo, la edad, el curso y la experiencia previa académica o profesional, de forma que las mejores autovaloraciones son realizadas por los hombres, las personas de mayor edad o curso superior, las que cuentan con una titulación universitaria previa o las que compaginan sus estudios con una actividad laboral de cara al público.

En cuanto a la valoración del alumnado de la formación recibida en los estudios universitarios, las actitudes son más críticas entre las mujeres. Se detecta, además, una correlación negativa entre esta actitud crítica y el curso académico, hasta el punto de que los estudiantes de $4^{\circ}$ curso considerarían insuficiente la formación en competencia oral recibida en la titulación. Sin embargo, estos resultados contrastan con los planes de estudio de Magisterio, en los que el desarrollo de las habilidades comunicativas ocupa un lugar destacado, aunque se produzca de forma implícita y transversal por medio de tareas de exposición oral y escrita. Los resultados revelan que este tratamiento es insuficiente, según la percepción del alumnado, por lo que parece necesario un planteamiento explícito de la competencia oral.

En este sentido, resulta oportuno fomentar la incorporación de actividades que promuevan una reflexión explícita por parte del alumnado sobre sus estrategias de comunicación oral en aquellas materias donde esta competencia se desarrolla de forma transversal e implícita tal y como recomienda Del Moral (2017). Además, dada la importancia que esta competencia tiene en el desarrollo profesional docente y según los resultados de trabajos previos, como los de Orejudo, Fernández-Turrado y Briz (2010), Romero et al. (2013) o Senís y Del Moral (2017), se considera pertinente incorporar en los planes de estudio del contexto de investigación una materia específica centrada en las habilidades comunicativas para docentes, una asignatura destinada a la reflexión explícita sobre el modo en el que el alumnado adquiere destrezas orales, sustentada en el necesario vínculo entre teoría y práctica que requiere la formación docente (MEZZAROBA; CARRIQUIRIBORDE, 2020).

Esta formación podría resultar de utilidad para su capacitación profesional, como muestran los resultados del estudio de Romero et al. (2013) a partir de una experiencia en los grados de Educación Infantil y Primaria en la Universidad del País Vasco. Entendemos esta propuesta como una aportación que contribuya a avanzar en 
la mejora de la formación inicial de las y los docentes, continuando la trayectoria recorrida en el Magisterio español durante ya más de dos siglos (SÁNCHEZ, E.; SÁNCHEZ, F., 2019).

Para finalizar, cabe reiterar que los resultados aportados son de tipo exploratorio y deben interpretarse con cautela. Así, este trabajo pretende abrir algunas líneas de investigación futuras, como la propia réplica del estudio con una muestra representativa complementada con un estudio cualitativo. El objetivo sería ahondar en las variables y claves que en esta investigación se han revelado como más significativas. Asimismo, nos parece oportuno, en la línea de Gallego y Rodríguez (2018), indagar sobre las percepciones del profesorado de Magisterio y contrastar los resultados con las valoraciones del alumnado para conocer de forma más integral el objeto de estudio y los efectos que generaría entre estudiantes y profesores la propuesta derivada de este primer estudio.

\section{Referencias}

BALAGUER, M. C.; FUENTES, M.; PALAU, M. La competencia oral en la formación inicial de maestros y maestras. Opción, v. 31, n. 5, p. 130-146, 2015.

BANDURA, A. Teoría del aprendizaje social. Madrid: Espasa Calpe, 1984.

BRUNER, J. Actos de significado: más allá de la revolución cognitiva. Madrid: Alianza, 1991.

BRUNER, J. El habla del niño: aprendiendo a usar el lenguaje. Madrid: Paidós, 1986.

DEL MORAL, C. El debate como estrategia formal para mejorar la competencia comunicativa de los futuros maestros. In: AGUILAR, A. M.; PEÑA, B. (Coord.). Didáctica de la lengua y la literatura: buenas prácticas docentes. Madrid: Asociación Cultural y Científica Iberoamericana, 2017. p. 80-111.

DEL MORAL, C.; SENÍS, J. Diseño y evaluación de un proceso de formación en habilidades comunicativas para la docencia. Porta Linguarum: Revista internacional de didáctica de las lenguas extranjeras, v. extra, n. 2, p. 57-71, 2017.

DOMINGO, J. et al. Competencias comunicativas de maestros en formación.

Profesorado: Revista de Currículum y Formación del Profesorado, Granada, v. 14, n. 2, p. 303-323, 2010. Disponible en: 10.5294/edu.2015.18.2.2. Acceso el: 9 jun. 2020. 
DOMINGO, J.; GALLEGO, J. L.; RODRÍGUEZ, A. Percepción del profesorado sobre la competencia comunicativa en estudiantes de magisterio. Perfiles Educativos, México, DF, v. 142, p. 54-74, 2013.

GALLEGO, J. L.; RODRÍGUEZ, A. Competencias comunicativas de maestros de educación especial. Educación y Educadores, v. 18, n. 2, p. 209-225, 2015.

GALLEGO, J. L.; RODRÍGUEZ, A. Percepción del alumnado universitario de Educación Física sobre su competencia comunicativa. Movimiento, Buenos Aires, v. 20, n. 2, p. 425444, 2014.

GALLEGO, J. L.; RODRÍGUEZ, A. Percepciones del profesorado sobre competencias comunicativas de futuros maestros de educación física. Revista Internacional de Medicina y Ciencias de la Actividad Física y el Deporte, Madrid, v. 18, n. 71, p. 479-492, 2018.

GRÀCIA, M. et al. La competencia comunicativa y lingüística en la formación inicial de maestros: un estudio piloto. Multidisciplinary Journal of School Education, v. 16, n. 2, p. 103-125, 2019. Disponible en: 10.14632/mjse.2019.16.103. Acceso el: 9 jun. 2020.

HERNÁNDEZ, R.; FERNÁNDEZ, C.; BAPTISTA, M. P. Metodología de la investigación. 6. ed. México, DF: McGraw Hill, 2014.

HERNÁNDEZ, R.; MENDOZA, C. P. Metodología de la investigación: las rutas cuantitativa, cualitativa y mixta. México, DF: McGraw Hill, 2018.

LOMAS, C.; OSORO, A.; TUSÓN, A. Ciencias del lenguaje, competencia comunicativa y enseñanza de la lengua. Barcelona: Paidós, 1993.

MATOS, D.; JARDILINO, J. R. L. Os conceitos de concepção, percepção, representação e crença no campo educacional: similaridades, diferenças e implicações para pesquisa. Educação \& Formação, Fortaleza, v. 1, n. 3, p. 20-31, 2016.

MEZZAROBA, C.; CARRIQUIRIBORDE, N. Teoría y práctica: cuestiones imprescindibles a la práctica educativa. Educação \& Formação, Fortaleza, v. 5, n. 15, p. 1-20, 2020.

OREJUDO, S.; FERNÁNDEZ-TURRADO, T.; BRIZ, E. Resultados de un programa para reducir el miedo y aumentar la autoeficacia para hablar en público en estudiantes universitarios de primer año. Estudios sobre Educación, v. 22, p. 199-217, 2012.

ROMERO, A. et al. Desarrollo de la competencia en comunicación lingüística en primer curso de los grados de educación infantil y educación primaria. Revista Internacional de Educación y Aprendizaje, La Rioja, v. 1, n. 2, p. 37-48, 2013.

ROSALES, C. Competencias específicas curriculares que ha de adquirir el estudiante del título de Grado de Maestro. Profesorado: Revista de Currículum y Formación del Profesorado, Granada, v. 17, n. 3, p. 73-90, 2013. 
SÁNCHEZ, E.; SÁNCHEZ, F. Una mirada a la trayectoria histórica de la formación de maestros en España durante los siglos XIX y XX. Educação \& Formação, Fortaleza, v. 4, n. 10, p. 18-49, 2019.

VYGOTSKY, L. S. El desarrollo de los procesos psicológicos superiores. 3. ed. Barcelona: Crítica, 2000.

\section{Anexo I - Cuestionario sobre la percepción de la competencia en comunicación oral del alumnado de Magisterio y de la formación recibida en sus estudios universitarios}

\begin{tabular}{|c|c|c|c|c|c|c|c|}
\hline Edad & Sexo & & Campus & & Grado & & Curso \\
\hline & Hombre & Mujer & Huesca & Zaragoza & Infanti & Primaria & \\
\hline
\end{tabular}

¿Has cursado una titulación previa?

\section{Sí. Otra carrera.}

\section{Sí. Formación} profesional.
No.
Si trabajas a la vez que estudias, ¿tu trabajo es de cara al público?
No trabajo.
Sí. Es de cara al público.
No.

\section{Escribe las lenguas que hablas} con una competencia bilingüe

\section{Escribe las lenguas en} las que tienes un título

Mención que cursas o cursarás

\begin{tabular}{|c|c|c|c|c|c|c|}
\hline & $\begin{array}{l}\text { Valoración de mi competencia comunicativa oral actual en mi vida cotidiana. } \\
\text { Competencia como emisor/a de mensajes orales. (1: Nunca-5: Siempre) }\end{array}$ & 1 & 2 & 3 & 4 & 5 \\
\hline 1 & $\begin{array}{l}\text { Me expreso oralmente con propiedad y corrección, utilizando las palabras } \\
\text { adecuadas para cada situación comunicativa. }\end{array}$ & & & & & \\
\hline 2 & Me siento seguro/a cuando tengo que iniciar una situación de comunicación oral. & & & & & \\
\hline 3 & $\begin{array}{l}\text { Articulo con coherencia y cohesión las ideas de lo que quiero expresar y las apoyo } \\
\text { con ejemplos. }\end{array}$ & & & & & \\
\hline 4 & $\begin{array}{l}\text { En general, considero que mi dominio de las habilidades comunicativas como } \\
\text { emisor/a es bueno. }\end{array}$ & & & & & \\
\hline & $\begin{array}{l}\text { Valoración de mi competencia comunicativa oral actual en mi vida cotidiana. } \\
\text { Competencia como receptor/a de mensajes orales. (1: Nunca-5: Siempre) }\end{array}$ & 1 & 2 & 3 & 4 & 5 \\
\hline 5 & $\begin{array}{l}\text { Me concentro en escuchar y me cercioro de que he comprendido al emisor antes de } \\
\text { emitir un juicio u opinión. }\end{array}$ & & & & & \\
\hline 6 & Me pongo en el lugar del otro para comprender mejor sus argumentos. & & & & & \\
\hline 7 & Descubro fácilmente el hilo conductor de lo que se me dice. & & & & & \\
\hline 8 & Presto atención al contexto para entender el significado de las palabras. & & & & & \\
\hline 9 & $\begin{array}{l}\text { En general, considero que mi dominio de las habilidades comunicativas como } \\
\text { receptor/a es bueno. }\end{array}$ & & & & & \\
\hline
\end{tabular}

Educ. Form., Fortaleza, v. 6, n. 1, e3490, jan./abr. 2021

DOI: https://doi.org/10.25053/redufor.v6i1.3490

https://revistas.uece.br/index.php/redufor/index 


\begin{tabular}{|c|c|c|c|c|c|c|}
\hline \multicolumn{2}{|r|}{$\begin{array}{l}\text { Valoración de mi competencia comunicativa oral como estudiante de Magisterio. } \\
\text { Competencia en situaciones académicas como estudiante. (1: Nunca-5: Siempre) }\end{array}$} & \multirow[t]{2}{*}{1} & \multirow[t]{2}{*}{2} & \multirow[t]{2}{*}{3} & \multirow[t]{2}{*}{4} & \multirow[t]{2}{*}{5} \\
\hline 10 & $\begin{array}{l}\text { En una presentación oral, organizo correctamente la información en el PPT (sin } \\
\text { exceso de letra, usando diferentes tipografías, etc.), pensando siempre en cómo } \\
\text { ayudará al destinatario a comprender o completar mi discurso oral. }\end{array}$ & & & & & \\
\hline 11 & $\begin{array}{l}\text { En una exposición oral, apoyo mi intervención en el PPT sin leer e hilando el } \\
\text { discurso y dinamizo mi intervención sirviéndome adecuadamente de gestos, } \\
\text { movimientos, etc. con naturalidad. }\end{array}$ & & & & & \\
\hline 12 & $\begin{array}{l}\text { En el aula (como estudiante), me expreso con naturalidad y sin inhibiciones delante } \\
\text { del grupo y profesor/a cuando la situación lo requiere (para opinar, } \\
\text { responder/formular preguntas, etc.). }\end{array}$ & & & & & \\
\hline 13 & $\begin{array}{l}\text { Me siento capaz de utilizar un registro académico ante una situación comunicativa } \\
\text { oral formal. }\end{array}$ & & & & & \\
\hline 14 & $\begin{array}{l}\text { En caso de haber defendido oralmente un trabajo ante un tribunal, he interactuado } \\
\text { con el tribunal con seguridad. (Si todavía no has vivido esa situación: indica en qué } \\
\text { medida crees que estás preparado/a para enfrentarte a esa situación con éxito). }\end{array}$ & & & & & \\
\hline 15 & $\begin{array}{l}\text { En caso de haber defendido oralmente un trabajo ante un tribunal: he dado } \\
\text { respuesta a las preguntas del tribunal argumentando con solidez mis respuestas. } \\
\text { (Si todavía no has vivido esa situación: indica en qué medida crees que estás } \\
\text { preparado/a para enfrentarte a esa situación con éxito). }\end{array}$ & & & & & \\
\hline 16 & $\begin{array}{l}\text { En general, considero que mi dominio de las habilidades comunicativas propias de } \\
\text { la vida académica como estudiante universitario/a es buena. }\end{array}$ & & & & & \\
\hline \multicolumn{2}{|r|}{$\begin{array}{l}\text { Valoración de mi competencia comunicativa oral interviniendo con el alumnado. } \\
\text { (Si no has hecho prácticas, piensa en qué medida te sientes preparado/a). (1: Poco-5: Mucho) }\end{array}$} & 1 & 2 & 3 & 4 & 5 \\
\hline 17 & $\begin{array}{l}\text { En el aula con mis alumnos/as, articulo clara y correctamente, a velocidad } \\
\text { moderada y con un tono de voz adecuado. }\end{array}$ & & & & & \\
\hline 18 & $\begin{array}{l}\text { Cuando doy clase a los niños/as, organizo adecuadamente mis exposiciones y uso } \\
\text { ejemplos adecuados al contenido impartido y al nivel de comprensión del } \\
\text { alumnado. }\end{array}$ & & & & & \\
\hline 19 & $\begin{array}{l}\text { Soy capaz de captar y mantener la atención del alumnado e incentivar su } \\
\text { participación. }\end{array}$ & & & & & \\
\hline 20 & $\begin{array}{l}\text { Me siento seguro/a para conducir el grupo clase sin una ayuda o supervisión de } \\
\text { otro/a docente. }\end{array}$ & & & & & \\
\hline 21 & $\begin{array}{l}\text { Cuando estoy realizando una explicación delante de mis alumnos/as, utilizo gestos } \\
\text { y otras expresiones corporales para mejorar la comunicación. }\end{array}$ & & & & & \\
\hline 22 & $\begin{array}{l}\text { En general, considero que mi dominio de los aspectos comunicativos de la labor } \\
\text { docente en el aula es bueno. }\end{array}$ & & & & & \\
\hline \multicolumn{2}{|r|}{$\begin{array}{c}\text { Valoración de mi competencia com. oral en otras situaciones de la vida escolar. (Si } \\
\text { no has hecho prácticas, piensa en qué medida te sientes preparado/a). (1:Poco-5: Mucho) }\end{array}$} & 1 & 2 & 3 & 4 & 5 \\
\hline 23 & $\begin{array}{l}\text { En general, considero que actualmente mi dominio de las habilidades para la } \\
\text { comunicación con las familias en tutorías es / sería bueno. }\end{array}$ & & & & & \\
\hline 24 & $\begin{array}{l}\text { En general, considero que actualmente mi dominio de las habilidades para la } \\
\text { comunicación en las reuniones con otros maestros (p.e. claustros) es / sería bueno. }\end{array}$ & & & & & \\
\hline 25 & $\begin{array}{l}\text { En general, considero que actualmente mi dominio de las habilidades para la } \\
\text { comunicación con un niño/a en una tutoría individual es / sería bueno. }\end{array}$ & & & & & \\
\hline \multicolumn{2}{|r|}{$\begin{array}{l}\text { Valoración de la formación recibida en los estudios universitarios en Magisterio. } \\
\text { (Las asignaturas cursadas en la carrera te han ayudado a desarrollar...) (1: Poco- } 5: \text { Mucho) }\end{array}$} & 1 & 2 & 3 & 4 & 5 \\
\hline 26 & Las habilidades para ser un/a buen/a emisor/a de mensajes orales. & & & & & \\
\hline 27 & Las habilidades para ser un/a buen/a receptor/a de mensajes orales. & & & & & \\
\hline 28 & Las habilidades para comunicarme oralmente en una situación académica formal & & & & & \\
\hline
\end{tabular}

Educ. Form., Fortaleza, v. 6, n. 1, e3490, jan./abr. 2021

DOI: https://doi.org/10.25053/redufor.v6i1.3490

https://revistas.uece.br/index.php/redufor/index 


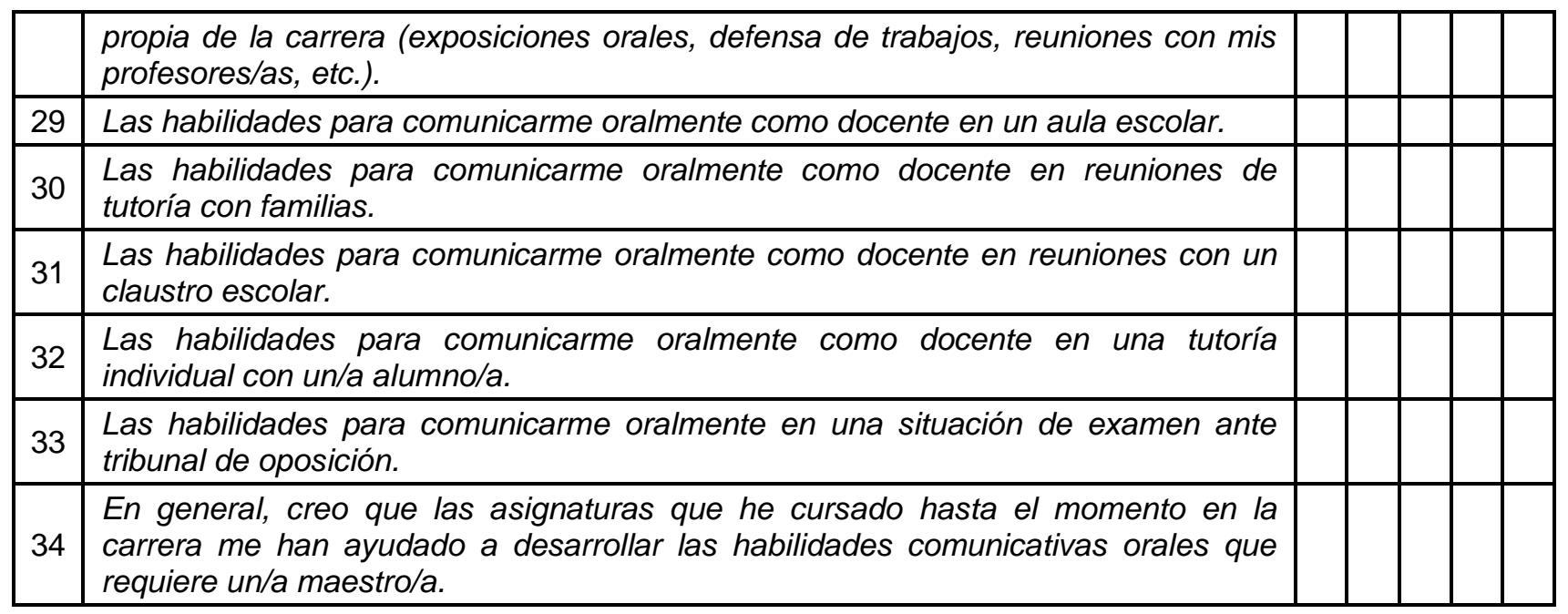

Añade cualquier comentario que consideres relevante en relación al objetivo del cuestionario:

\footnotetext{
Iris Orosia Campos Bandrés, Universidad de Zaragoza, Departamento de Didácticas Específicas iDhttps://orcid.org/0000-0003-2039-031X

Doctora en Educación por la Universidad de Zaragoza. Profesora del área de Didáctica de la Lengua y la Literatura y directora del Diploma de Especialización en Filología Aragonesa de la Universidad de Zaragoza. Miembro del grupo de investigación de referencia Educación Comunicativa y Literaria en la Sociedad de la Información, Literatura Infantil y Juvenil en la Construcción de Identidades (ECOLIJ). Líneas de investigación: enseñanza de lenguas, literatura infantil y juvenil, sociolingüística educativa, lenguas minoritarias y multilingüismo.

Contribución de autoría: Administración del proyecto, análisis formal, curaduría de datos, concepto, primera redacción, investigación, metodología, financiación, recursos, software, supervisión, validación y visualización.

E-mail: icamposb@unizar.es
}

\section{María Jesús Colón Castillo, Universidad de Zaragoza, Departamento de Didácticas Específicas ii(-)https://orcid.org/0000-0003-0942-1840}

Profesora del área de Didáctica de la Lengua y la Literatura en la Facultad de Educación de la Universidad de Zaragoza. Miembro del grupo de investigación de referencia Educación Comunicativa y Literaria en la Sociedad de la Información, Literatura Infantil y Juvenil en la Construcción de Identidades (ECOLIJ). Líneas de investigación: formación de lectores, lectura en contextos rurales, álbum sin palabras y didáctica del idioma.

Contribución de autoría: Concepto, revisión y edición, investigación, financiación, recursos, supervisión, validación, visualización.

E-mail:mjcolon@unizar.es 
Marta Sampériz Hernández, Universidad de Zaragoza, Departamento de Didácticas Específicas iii iD https://orcid.org/0000-0003-2624-7477

Investigadora del área de Didáctica de la Lengua y la Literatura en la Facultad de Ciencias Humanas y de la Educación de la Universidad de Zaragoza. Miembro del grupo de investigación de referencia Educación Comunicativa y Literaria en la Sociedad de la Información, Literatura Infantil y Juvenil en la Construcción de Identidades (ECOLIJ). Líneas de investigación: estudios teóricos del libro de no ficción y lectura en el medio rural.

Contribución de autoría: Administración del proyecto, concepto, revisión y edición, investigación, financiación, recursos, supervisión, validación y visualización.

E-mail: martasamperiz@unizar.es

Editora responsable: Lia Machado Fiuza Fialho

Pareceristas ad hoc: Cristina del Moral-Barrigüete y Antonio Gutiérrez Rivero

\section{Cómo citar este artículo (ABNT):}

CAMPOS BANDRÉS, Iris Orosia; COLÓN CASTILLO, María Jesús; SAMPÉRIZ HERNÁNDEZ, Marta. Diseño de un cuestionario para valorar la competencia en comunicación oral del alumnado de Magisterio. Educ. Form., Fortaleza, v. 6, n. 1, e3490, 2020. Disponible en: https://revistas.uece.br/index.php/redufor/article/view/3490

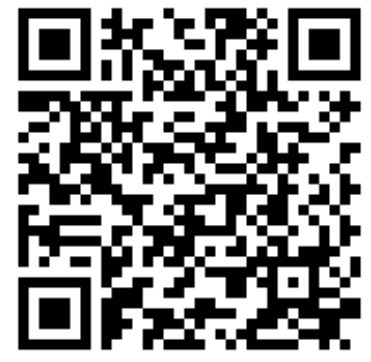

Recibido el 7 de julio de 2020.

Aceptado el 4 de agosto de 2020.

Publicado el 19 de octubre de 2020. 